\title{
A new albedo parameterization for use in climate models over the Antarctic ice sheet
}

\author{
P. Kuipers Munneke, ${ }^{1}$ M. R. van den Broeke, ${ }^{1}$ J. T. M. Lenaerts, ${ }^{1}$ M. G. Flanner, ${ }^{2}$
} A. S. Gardner, ${ }^{2,3}$ and W. J. van de Berg ${ }^{1}$

Received 24 September 2010; revised 6 December 2010; accepted 3 January 2011; published 10 March 2011.

[1] A parameterization for broadband snow surface albedo, based on snow grain size evolution, cloud optical thickness, and solar zenith angle, is implemented into a regional climate model for Antarctica and validated against field observations of albedo for the period 1995-2004. Over the Antarctic continent, modeled snow grain size exhibits expected behavior. The agreement between modeled and observed albedo at Neumayer, Dronning Maud Land, is very good, and subtle variability in albedo is well captured by the model. December-February mean differences in modeled and observed net shortwave radiation range from -8.7 to $+3.8 \mathrm{~W} \mathrm{~m}^{-2}$ between 1995 and 2004, with a mean value of $-2.7 \mathrm{~W} \mathrm{~m}^{-2}$. This is a considerable improvement compared to the previous albedo parameterization in the model, which led to overestimates of the net shortwave fluxes by +15.0 to $+22.7 \mathrm{~W} \mathrm{~m}^{-2}$, or $40-55 \%$ of the observed net shortwave flux, in the same period.

Citation: Kuipers Munneke, P., M. R. van den Broeke, J. T. M. Lenaerts, M. G. Flanner, A. S. Gardner, and W. J. van de Berg (2011), A new albedo parameterization for use in climate models over the Antarctic ice sheet, J. Geophys. Res., 116, D05114, doi:10.1029/2010JD015113.

\section{Introduction}

[2] At present, runoff of meltwater does not constitute a major component in the mass budget of the Antarctic ice sheet [van den Berg et al., 2006]. Mass gained by snowfall is mainly lost by the shedding of ice bergs off ice shelves that surround most of the continent. That said, persistent snow melt occurs annually in large parts of coastal Antarctica, in the Antarctic Peninsula, and on the surface of the ice shelves [Tedesco et al., 2007]. Much of this meltwater refreezes locally. However, estimating present and future quantities of this local meltwater production is important for at least two reasons.

[3] First of all, local melting of surface snow lowers snow albedo. Since the albedo of snow is so high, a small decrease in surface albedo already implies a large change in the net solar radiation budget of the snowpack. An increase in absorbed solar radiation provides energy for the melt of more snow. In this way, the entire energy budget of the snowpack is prone to changes that may amplify themselves. Of particular interest is to assess how the energy budget of Antarctic snow will develop in a future climate. Temperatures over parts of the Antarctic continent are reported to have increased strongly in the last 50 years [Meredith and

\footnotetext{
${ }^{1}$ Institute for Marine and Atmospheric Research, Utrecht University, Utrecht, Netherlands.

${ }^{2}$ Department of Atmospheric, Oceanic, and Space Sciences, University of Michigan, Ann Arbor, Michigan, USA.

${ }^{3}$ Department of Earth and Atmospheric Sciences, University of Alberta, Edmonton, Alberta, Canada.

Copyright 2011 by the American Geophysical Union. 0148-0227/11/2010JD015113
}

King, 2005; Steig et al., 2009]. Higher temperatures may in general lead to lower snow albedo. On the other hand, a possible increase in precipitation rates may have the opposite effect. Future scenario runs with climate models over the Antarctic continent therefore require a reliable snow albedo scheme.

[4] Secondly, it has been hypothesized that surface meltwater accumulation plays a crucial role in the breakup of ice shelves [Scambos et al., 2000]. Recently, the collapse of the Larsen B ice shelf was preceded by an unusual rate of melt water production [van den Broeke, 2005]. This meltwater may have filled and deepened crevasses until they opened up all the way to the bottom, leading to the complete elimination of ice shelves. In the years following the Larsen B collapse, glaciers previously feeding the ice shelf sped up considerably [De Angelis and Skvarça, 2003; Rignot et al., 2004]. Through this 'melt pond theory,' surface melt on ice shelves can have profound effects on the dynamical response of large parts of the coastal ice sheet to climate change.

[5] In this paper, we discuss the implementation and validation of an improved snow albedo scheme in the regional climate model RACMO2.1. This model, developed at the Royal Netherlands Meteorological Institute (KNMI), is an amalgam of the atmospheric dynamics part of the HIRLAM model [Undén et al., 2002] and the physics of atmosphere and land surfaces from the ECMWF climate model [White, 2001]. For the application of RACMO2.1 in polar regions, adaptations have been made for specific polar meteorological processes. Among these is the implementation of a multilayer snow model [Ettema et al., 2009]. The snow model solves the snowpack thermodynamics and hydrodynamics, including melt water retention, percolation, 
refreezing, and runoff. First, we will discuss the old albedo parameterization in RACMO2.1 and similar ones in other models, after which we will present the improved albedo parameterization, as well as results from a model run between 1989 and 2009, compared to field data of albedo.

\section{Existing Albedo Parameterizations}

[6] Accurately simulating surface snow albedo in climate models is both crucial and challenging. Absorbed solar radiation is a dominant term in the summer energy budget of glaciers and ice sheets, and subject to strong feedbacks. These feedbacks consist mainly of an interaction between shortwave radiation and the size of the grains that make up the snowpack: the photon path length within ice is greater in large-grained snow, increasing the probability of absorption and producing lower albedo. In turn, absorbed solar radiation provides energy for the growth of the snow grains, and for melt and refreezing of snow. These mechanisms constitute positive feedbacks that are delicate to implement in parameterizations for snow albedo. The most physical way to approach the construction of an albedo parameterization is therefore to incorporate snow grain size prognostically, and relate snow albedo to grain size evolution.

[7] Rather, albedo parameterizations in many climate models are based on some sort of proxy variables for snow grain size or its evolution. There is some physical justification for using these proxies, but all have their limitations and shortcomings. For example, some parameterizations are based on snow temperature [Verseghy, 1991; Roeckner et al., 2003; Bougamont et al., 2005; Reijmer et al., 2005] based on the idea that snow grain size increases faster at higher temperatures. Indeed, the albedo decay in most of these parameterizations goes faster when the snow is warmer.

[8] Another example of such a proxy is snow density. This approach has been developed by Greuell and Konzelmann [1994] and implemented in the regional atmospheric climate model RACMO2.1 for a climate reanalysis over the Greenland ice sheet [Ettema et al., 2009]. The rationale for this approach is that fresh snow is light, and that density increases with time and after refreezing of melt water, exactly like snow grain size. Moreover, densification, like snow metamorphism, tends to be irreversible for fallen snow.

[9] The application of the density-based albedo to the Greenland ice sheet [Ettema et al., 2009] revealed that it does a good job at capturing roughly the transition from snow to ice surface, and the accompanying dramatic changes in the surface energy budget in the Greenland ablation area. But already here, the simulation of wet snow albedo is somewhat problematic as the density is too sensitive a predictor for albedo [Fettweis et al., 2010]. For the same reason, the density-based parameterization falls short when applied to the Antarctic continent, where feedbacks in the current climate are more subtle at present. In Figure 1, we show the results of a run with the RACMO2.1 model over the Antarctic continent using the density-based albedo parameterization. For visual clarity, the period in Figure 1 is limited to 5 years (1999-2004) for which there are both model results and observations. Compared to observations of snow albedo, a few things catch the eye. First of all, the modeled albedo in summer is consistently too low, despite imposing a minimum albedo of 0.70 , without which the albedo would drop even lower. Clearly, the albedo is too sensitive to density, or rather, the densification process is too sensitive to temperature and melt. Secondly, the variability of the modeled albedo is too low. Thirdly, the albedo under cloudy conditions, clearly visible as the upper limit of 0.85 , is too low compared to the observations. These shortcomings lead to an overestimation of net shortwave radiation of up to $22.7 \mathrm{~W} \mathrm{~m}^{-2}$ (Figure 1) averaged over an entire austral summer (DJF), corresponding to a rather discomforting overestimation of $40-55 \%$ relative to the observed net shortwave radiation flux. An improved albedo scheme is obviously needed if we want to simulate the surface energy balance of the Antarctic snowpack realistically.

\section{A New Albedo Parameterization}

[10] Snow albedo is dominantly dependent on the size of the snow grains, but also affected by cloud cover, solar zenith angle, and snow contamination by soot and dust. Ideally, a parameterization of snow albedo should depend on these four quantities. Such a parameterization has recently been developed by Gardner and Sharp [2010], based on extensive computations with a spectral radiative transfer model. At present, RACMO2.1 does not have a prognostic scheme for dust and soot deposition. However, as concentrations of these are very low on the Greenland and Antarctic ice sheets, neglecting their effects is acceptable. Cloud optical thickness and solar zenith angle are readily available in RACMO2.1. Since snow grain size was not computed so far in RACMO2.1, we will present here a prognostic scheme for the computation of snow grain size that permits the implementation of a physically based albedo parameterization. The evolution of snow grain size is based on the Snow, Ice, and Aerosol Radiative (SNICAR) model [Flanner and Zender, 2006]. A part of the scheme presented below is also implemented in version 4.0 of the NCAR Community Land Model (CLM 4.0) [Lawrence et al., 2011; Oleson et al., 2010].

\subsection{Evolving Snow Grain Size}

[11] The effect of snow grain size, $r_{e}$, on surface albedo is incorporated in RACMO2.1 by implementing snow grain size as a new prognostic variable. The quantity $r_{e}$ is known as the effective snow grain size, or the surface areaweighted mean grain size of a collection of ice particles. This metric of snow grain size has been shown to have most utility for radiative transfer in snow [Mitchell, 2002; Grenfell and Warren, 1999; Neshyba et al., 2003]. The evolution of grain size consists of dry snow metamorphism, wet snow metamorphism, and refreezing of liquid water in the snow matrix.

[12] Aging of dry snow is modeled in a microphysical way by the SNICAR model [Flanner and Zender, 2006], based on the computation of diffusive vapor fluxes amongst collections of ice crystals. The rate of crystal growth depends on snow temperature, local snow temperature gradient, and snow density. Parametric curves have been fitted to results of SNICAR as the full model is currently too computationally expensive. The parameterization takes the following form:

$$
\frac{d r_{e, d r y}}{d t}=\left(\frac{d r_{e}}{d t}\right)_{0}\left(\frac{\eta}{\left(r_{e}-r_{e, 0}\right)+\eta}\right)^{1 / \kappa}
$$




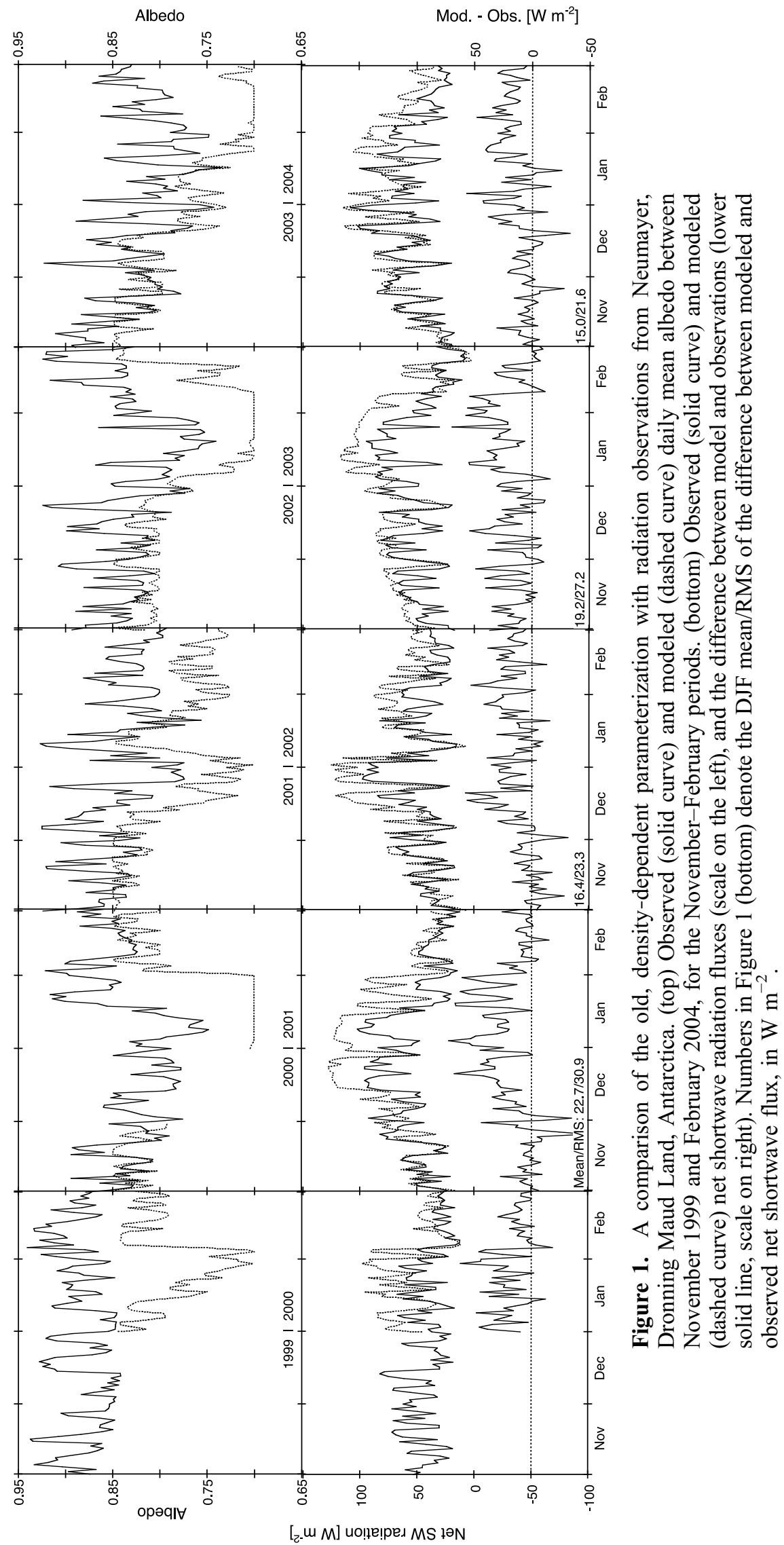




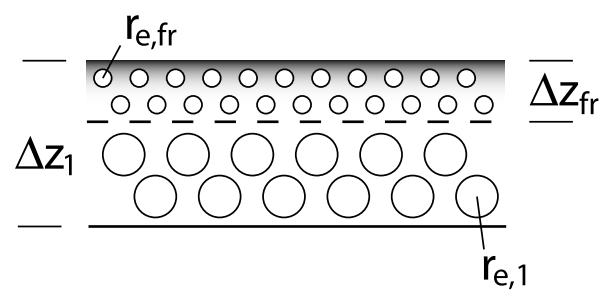

$\Delta \mathrm{z}_{2}$

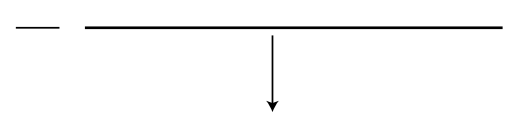

Figure 2. Handling of fresh snow and the top snow layer. Within the top layer $\Delta z_{1}$ having grain size $r_{e, 1}$, we keep track of the amount of fresh snow $\Delta z_{f r}$ with grain size $r_{e, f r}$. For thermodynamical computation, $\Delta z_{1}$ is used entirely, while for albedo calculations, $\Delta z_{f r}$ is taken into account separately as the top layer.

where $r_{e, 0}$ is the initial size of fresh snow grains. The coefficients $\left(d r_{e} / d t\right)_{0}, \eta$ and $\kappa$ are retrieved from a lookup table with the three dimensions temperature $(T)$, temperature gradient $(d T / d z)$, and density $(\rho)$. The fit of the parameterized curves to the SNICAR results is very accurate, with a root mean square error for $r_{e}$ of $3.2 \mu$ m over 2728 simulations of a 14 day period each, and a mean bias (parametric fit minus full SNICAR results) of $1.7 \mu \mathrm{m}$. These errors are much smaller than the uncertainties involved in the microphysics of the SNICAR model itself [Flanner and Zender, 2006]. However, in this study we adopt the parameterization based on the model configuration as presented by Flanner and Zender [2006], which is to some extent validated against laboratory and field data.

[13] The presence of liquid water has been shown to increase the snow grain growth rate considerably [Brun et al., 1989]. Wet snow metamorphism is parameterized based on equations by Brun et al. [1989] that relate changes in $r_{e}$ (in meters) to the liquid water content $f_{\text {liq }}$ :

$$
\frac{d r_{e, w e t}}{d t}=\frac{C f_{l i q}^{3}}{4 \pi r_{e}^{2}} .
$$

[14] In this equation, $C$ is constant at $4.22 \times 10^{-13} \mathrm{~m}^{3} \mathrm{~s}^{-1}$ [Brun et al., 1989].

[15] Furthermore, the grain size for refrozen liquid water $\left(r_{e, r}\right)$ is taken as $1500 \mu \mathrm{m}$. This is a somewhat arbitrary choice, as there is no source we know of that provides values for the size of refrozen snow grains. Old snow has a grain size of typically $1000 \mu \mathrm{m}$ [Wiscombe and Warren, 1980], suggesting that refrozen snow grains must be larger.

[16] The combined effect of these three mechanisms is computed each time step using

$$
r_{e}(t)=\left[r_{e}(t-1)+d r_{e, d r y}+d r_{e, w e t}\right] f_{o}+r_{e, 0} f_{n}+r_{e, r} f_{r},
$$

where $f_{o}, f_{n}$ and $f_{r}$ are the fractions of old, new, and refrozen snow in a snow layer, respectively. The value for $r_{e, 0}$ is set to $54.5 \mu \mathrm{m}$, corresponding to a specific surface area of $60 \mathrm{~m}^{2} \mathrm{~kg}^{-1}$ if the density of ice is taken as $917 \mathrm{~kg} \mathrm{~m}^{-3}$. This value for $r_{e, 0}$ is in line with the mean snow grain size of $50-55 \mu \mathrm{m}$ over the Antarctic Plateau as provided by the MODIS snow grain size product [Scambos et al., 2007]. The results are likely somewhat sensitive for the choice of $r_{e, 0}$ (and also $r_{e, r}$ ), but we did not test this for computative reasons.

\subsection{The Top Snow Layer}

[17] In order to guarantee numerical stability of the thermodynamical part of the snow scheme, the minimum thickness of a snow layer cannot be smaller than $z_{\min }$. A time step of $5 \mathrm{~min}$ implies $z_{\min }=4.0 \mathrm{~cm}$. Below this thickness, a layer is merged with another layer. However, within one time step the amount of snow accumulation will rarely suffice to create a separate new layer. For that reason, a fresh snow amount in the top layer is separately registered, and added as a regular layer whenever its thickness exceeds $z_{\min }$ (see Figure 2 for an illustration). Likewise, we have introduced a snow grain size of the fresh snow, on which metamorphism acts separately. When the fresh snow layer is merged with an older layer, the snow grain size of the new layer is computed as a mass-weighted average of the old and the fresh snow. This approach ensures that, although a thin fresh snow layer has no impact on the thermodynamics, it does immediately help to increase the albedo.

\subsection{Albedo Parameterization}

[18] A useful parameterization of broadband snow albedo $(\alpha)$ depending on snow grain size, cloud optical thickness $(\tau)$, and solar zenith angle $\left(u \equiv \cos \theta_{0}\right)$, is provided by Gardner and Sharp [2010],

$$
\alpha=\alpha_{S}+d \alpha_{u}+d \alpha_{c}+d \alpha_{\tau} .
$$

[19] In this formulation, $\alpha_{S}$ is a base albedo due to snow grain size, increased by contributions due to the zenith angle $\left(d \alpha_{u}\right)$, impurities $\left(d \alpha_{c}\right)$, and clouds $\left(d \alpha_{\tau}\right)$. Assuming that impurity content is negligible, the relevant equations for $\alpha$ become

$$
\begin{gathered}
\alpha_{S}=1.48-1.27048 r_{e}^{0.07} \\
d \alpha_{u}=0.53 \alpha_{S}\left(1-\alpha_{S}\right)(1-0.64 x-(1-x) u)^{1.2} \\
d \alpha_{c}=0 \\
d \alpha_{\tau}=\frac{0.1 \tau \alpha_{S}^{1.3}}{(1+1.5 \tau)^{\alpha_{S}}}
\end{gathered}
$$

where $x=\min (\sqrt{\tau / 3 u}, 1)$.

[20] The albedo of a thin layer of snow is influenced by the albedo of the underlying surface. The same is true for the albedo of a thin fresh snow layer on top of a layer containing older snow, or in general, of a thin layer of snow overlaying a layer of snow with different optical properties. It is assumed that the effect of an underlying layer decreases exponentially with depth below the surface [Oerlemans and 


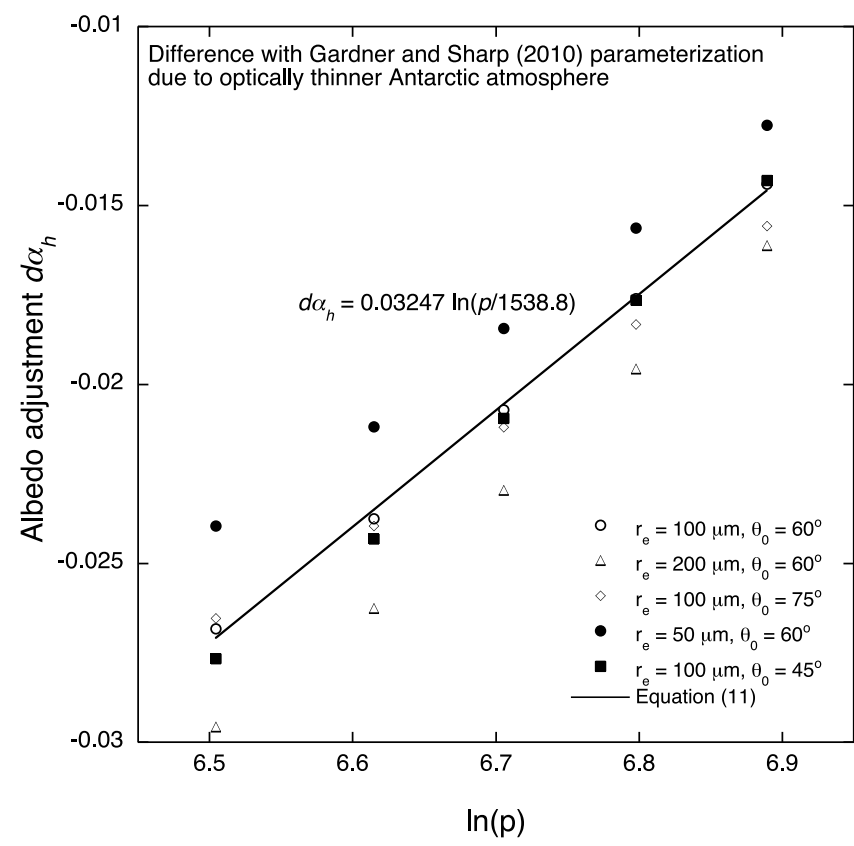

Figure 3. Albedo correction $d \alpha_{h}$ as a function of surface pressure $p(\mathrm{hPa})$. The albedo correction is needed as the Gardner and Sharp [2010] parameterization is based on an atmosphere that is optically thicker than the average Antarctic summer atmosphere.

Knap, 1998]. For two layers, the resulting albedo is written as

$$
\alpha=\alpha_{1}+\left(\alpha_{2}-\alpha_{1}\right) e^{-z / z_{\star}}
$$

[21] For $n$ layers of thickness $\Delta z$, the expression becomes

$$
\alpha=\alpha_{1}+\sum_{i=2}^{n}\left(\alpha_{i}-\alpha_{i-1}\right) \exp \left(-\sum_{j=1}^{i-1} \Delta z_{j} / z_{\star}\right) .
$$

[22] In RACMO2.1, we compute the albedo for $n=5$ layers (including the fresh snow layer if present) and assume $z_{\star}=1 \mathrm{~cm}$. Theoretically, there are some severe issues with assuming an exponential decay for the influence of a lower layer on broadband surface albedo. The value for $z_{\star}$ is strongly wavelength-dependent. It can be demonstrated with a radiative transfer model (e.g., like Kuipers Munneke et al. [2008] and Gardner and Sharp [2010]) that the albedo of a thin fresh snow layer on top of bare ice is actually higher than predicted with equation (9). However, the discrepancy between full radiative transfer calculations and the exponential decay approximation becomes much smaller when the albedo of the lower layer is not much different from that of the upper layer. This is the case for the present-day Antarctic snowpack, where the lower layer almost always consists of older, coarser-grained snow, and the upper layer of fresher snow. The formulation in equations (9) and (10) is therefore acceptable. For applications of RACMO2.1 over areas with bare ice, the exponential decay in equations (9) and (10) must be replaced by another formulation, like the one in equation (13) of Gardner and Sharp [2010].
[23] The cloud optical thickness $(\tau)$ is computed using the vertically integrated cloud water and cloud ice content and ranges between 0 and 40 over the continent, with high values near the coast, over the ice shelves, and in the Antarctic Peninsula.

\subsection{Clear-Sky Adjustment}

[24] The parameterization by Gardner and Sharp [2010] is developed for the standard AFGL (Air Force Geophysical Laboratory) subarctic summer atmosphere (SAS) [Anderson et al., 1986] for a snow surface at sea level. It has been shown however, that the optical thickness of the atmospheric clearsky column has a small but important impact on surface albedo [Kuipers Munneke et al., 2008]. This effect is of spectral nature: an optically thin atmosphere transmits more near-infrared radiation (wavelengths $>800 \mathrm{~nm}$ ) to the surface for which the spectral albedo of snow is low: the broadband albedo therefore decreases.

[25] Since the typical Antarctic atmosphere is much colder than the SAS atmosphere, and therefore contains much less water vapor, clear-sky snow albedo is expected to be lower in Antarctica than computed by the Gardner and Sharp [2010] parameterization. The decrease becomes larger as the atmosphere becomes thinner, i.e., as surface elevation increases. As a simple solution, we therefore adjust their parameterization downward by a factor $d \alpha_{h}$ depending on the surface pressure $p$. Using the radiative transfer model DAK [Kuipers Munneke et al., 2008], we computed the albedo differences between the SAS atmosphere and typical Antarctic summer atmospheres at surface elevations between 0 and $3000 \mathrm{~m}$ above sea level (982 to $668 \mathrm{hPa}$ ). The resulting correction function

$$
d \alpha_{h}=0.03247 \ln \left(\frac{p}{1538.8}\right)
$$

is shown in Figure 3. The relation between $p$ and $d \alpha_{h}$ is somewhat dependent on the values for $u, r_{e}$ and $\tau$. In Figure $3, d \alpha_{h}$ is shown as a series of symbols for five combinations of $u$ and $r_{e}$. For the combinations shown in Figure 3, the deviation from equation (11) is at maximum about 0.003 . In general, the equation captures the desired effect of decreasing albedo with decreasing atmospheric optical thickness.

\section{Results and Discussion}

[26] RACMO2.1 was run for the period 1 January 1989 to 31 December 2009 at a horizontal resolution of $27 \mathrm{~km}$, forced with ERA Interim reanalysis data at the lateral domain boundaries. During a typical summer season, illustrated by the austral summer of 2001-2002 in Figures 4a-4f, snow grain size in the uppermost snow layers is uniformly small in October (Figure 4a) and starts to increase on the Antarctic Peninsula in November (Figure 4b). From December (Figure 4c), snow grain size starts to increase in the area of Pine Island glacier and the Abbot ice shelf north of Ellsworth Land. This increase continues into January (Figure 4d) and February (Figure 4e) while snow grain size increase also becomes visible on the Amery and FilchnerRonne ice shelves, in the area of Siple Dome, as well as in the coastal regions of Dronning Maud Land. Snow grain size peaks on the Antarctic Peninsula at more than $600 \mu \mathrm{m}$. 


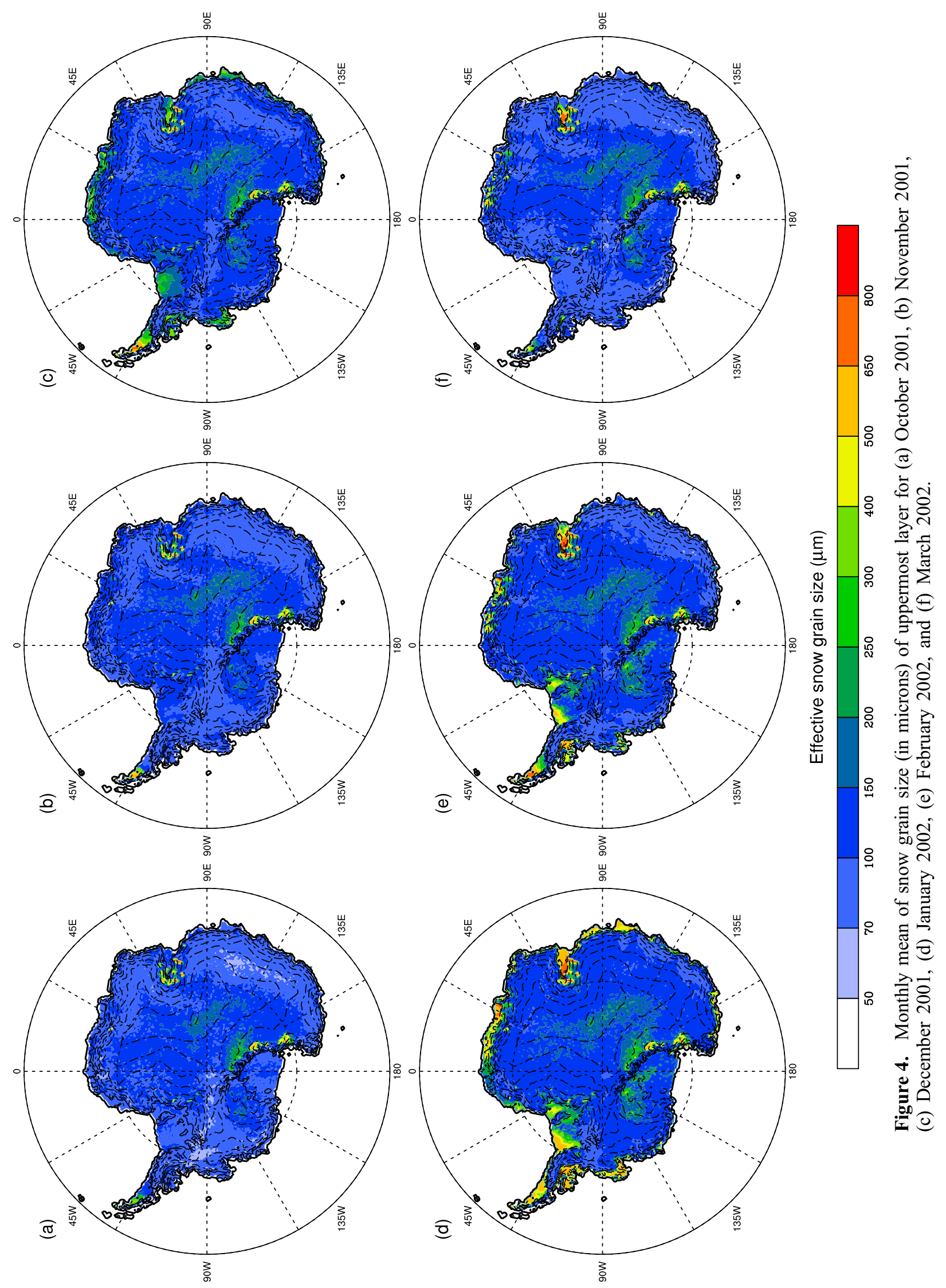




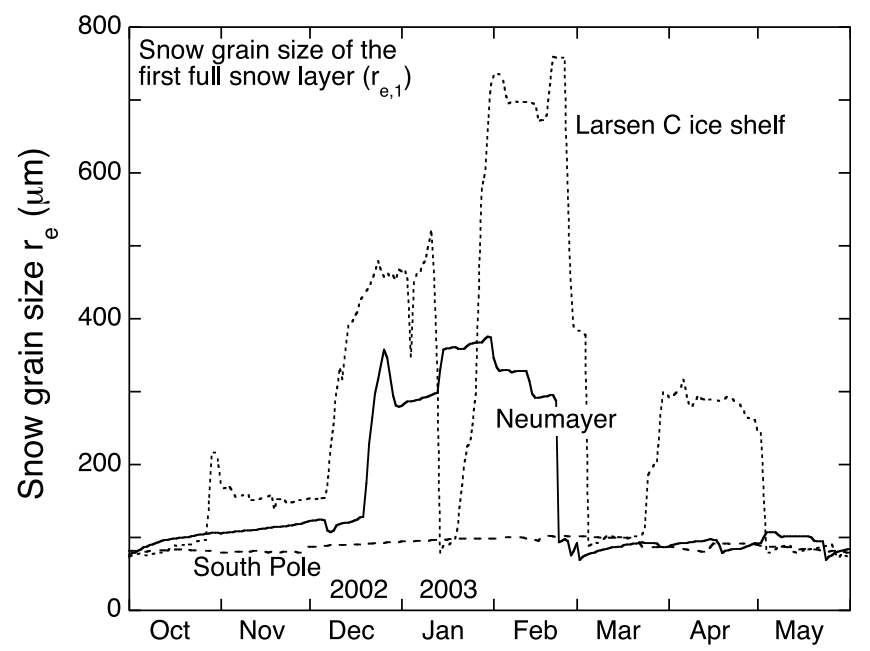

Figure 5. Snow grain size $(\mu \mathrm{m})$ in the uppermost full snow layer $\left(r_{e, 1}\right)$ at three locations during a summer season: South Pole (long-dashed curve), Neumayer (solid curve), and Larsen $\mathrm{C}$ ice shelf (short-dashed curve).

From March (Figure 4f) onward, fresh snow fall decreases the snow grain size everywhere.

[27] Zooming in on snow grain size evolution at specific sites, an example of the evolution of snow grain size in the uppermost snow layer is shown in Figure 5 for three very different locations. At South Pole, there is very little metamorphism since snow temperature on the Plateau remains low in summer. Therefore, snow grains remain small. There is so little snowfall at South Pole that the top snow layer gets refreshed only a few times between October 2002 and June 2003. At Neumayer in coastal Dronning Maud Land, the start of a warmer period is marked by a stepwise increase in snow grain size in December 2002, associated with wet snow metamorphism and refreezing of meltwater. In February, the uppermost snow layer is filled with fresh snow again, and grain size drops back to values around $100 \mu \mathrm{m}$. The higher accumulation rate at Neumayer is reflected in frequent downward stepping of snow grain size. On the Larsen $\mathrm{C}$ ice shelf in the Antarctic Peninsula, large snow grains are sustained by high metamorphism rates and multiple refreezing events between November and April. Copious amounts of snowfall are reflected in very frequent downward stepping of grain size. In January, a snowfall events briefly fills the uppermost snow layer with fresh snow, after which the presence of meltwater rapidly increases the grain size. Maximum grain sizes in the period shown in Figure 5 are $102 \mu \mathrm{m}$ at South Pole, $375 \mu \mathrm{m}$ at Neumayer, and $759 \mu \mathrm{m}$ at Larsen C.

[28] There are few high-quality shortwave radiation data available in Antarctica to validate the improved albedo parameterization. The best series are from the BSRN (Baseline Surface Radiation Network [Ohmura et al., 1998]) site at Neumayer, Antarctica. In Figure 6 (top), daily mean observed and modeled albedo are compared for the November-February periods between 1999 and 2004. For visual clarity, the period in Figure 6 is limited to 5 years, while the overlap between observations and model results is
10 years (1995-2004). In a relatively cold summer (19992000 ), there is little melt and the albedo remains above 0.80 throughout the season. Model results follow the observations well: the variability due to cloud cover is well captured. In warmer summers (2000-2001 and 2003-2004), small amounts of melt water lower the albedo, initiating a delicate feedback between melt water and albedo decrease. This feedback is remarkably well captured by the model: the modeled albedo does not tend to run away, and shows variability that is comparable to observations.

[29] There are periods for which the observed and simulated albedos diverge, like in January 2003 (Figure 6): the drop in albedo from values around $0.85-0.90$ to $0.75-0.80$ seen in the observations is missed by the model. As a result, the energy flux delivered to the snowpack is underestimated: expressed as a DJF mean, the model underestimates net shortwave radiation by $5.7 \mathrm{~W} \mathrm{~m}^{-2}$. There are many possible causes for such a mismatch: a snowfall event in the model that was not observed, delivering fresh snow and preventing the strong albedo-melt feedback; or differences in modeled and observed cloud cover leading to lower modeled surface temperatures. Considering the amount of freedom in the atmospheric model, as well as considering the strong feedback between albedo and melt, the main conclusion is still that overall agreement is good, bearing in mind that deviations of the model from observations cannot be avoided.

[30] In Figure 6 (bottom), modeled and observed net shortwave radiation fluxes at Neumayer are compared. For the period shown in Figure 6, the DJF mean differences are between -8.7 and $-1.1 \mathrm{~W} \mathrm{~m}^{-2}$. For the entire period 1995 2004 , the DJF mean differences lie between $-8.7 \mathrm{~W} \mathrm{~m}^{-2}$ and $+3.8 \mathrm{~W} \mathrm{~m}^{-2}$, with a mean value of $-2.7 \mathrm{~W} \mathrm{~m}^{-2}$. This is a considerable improvement compared to the old, densitydependent parameterization. For the years shown in Figure 6, the RMS of the difference is between 17.5 and $24.8 \mathrm{~W} \mathrm{~m}^{-2}$, largely made up of a random fluctuation around the mean. This fluctuation originates from the fact that modeled cloud cover differs from observed cloudiness, causing differences in modeled and observed net shortwave radiation at the surface. The variability of both the albedo and the net shortwave flux is very well captured by the model, and much better than by the density-dependent parameterization.

[31] For the purpose of illustrating the behavior of model albedo in different climate regimes, Figure 7 shows the albedo as simulated from 1999 up to and including 2004 for the same locations as shown in Figure 5. The albedo at South Pole (in gray) is somewhat lower than at Neumayer due to the thinner atmospheric column (section 3.4), although this is partly compensated by an albedo increase due to the lower solar elevation at South Pole. The variability due to clouds is much smaller than at Neumayer, since cloud optical thickness is much smaller at South Pole. The Larsen C Ice Shelf, also shown in Figure 7 but shifted downward by 0.10 for clarity, regularly experiences some surface melt, causing the period with lower albedo to be longer than at Neumayer. In some years, there is (almost) no melt at Neumayer but sustained melt at Larsen C, for example, the austral summer of 1999-2000. Although ponding of meltwater is known to occur on ice shelves [van den Broeke, 2005], its effect on surface albedo is not incorporated in the albedo parameterization at present. 


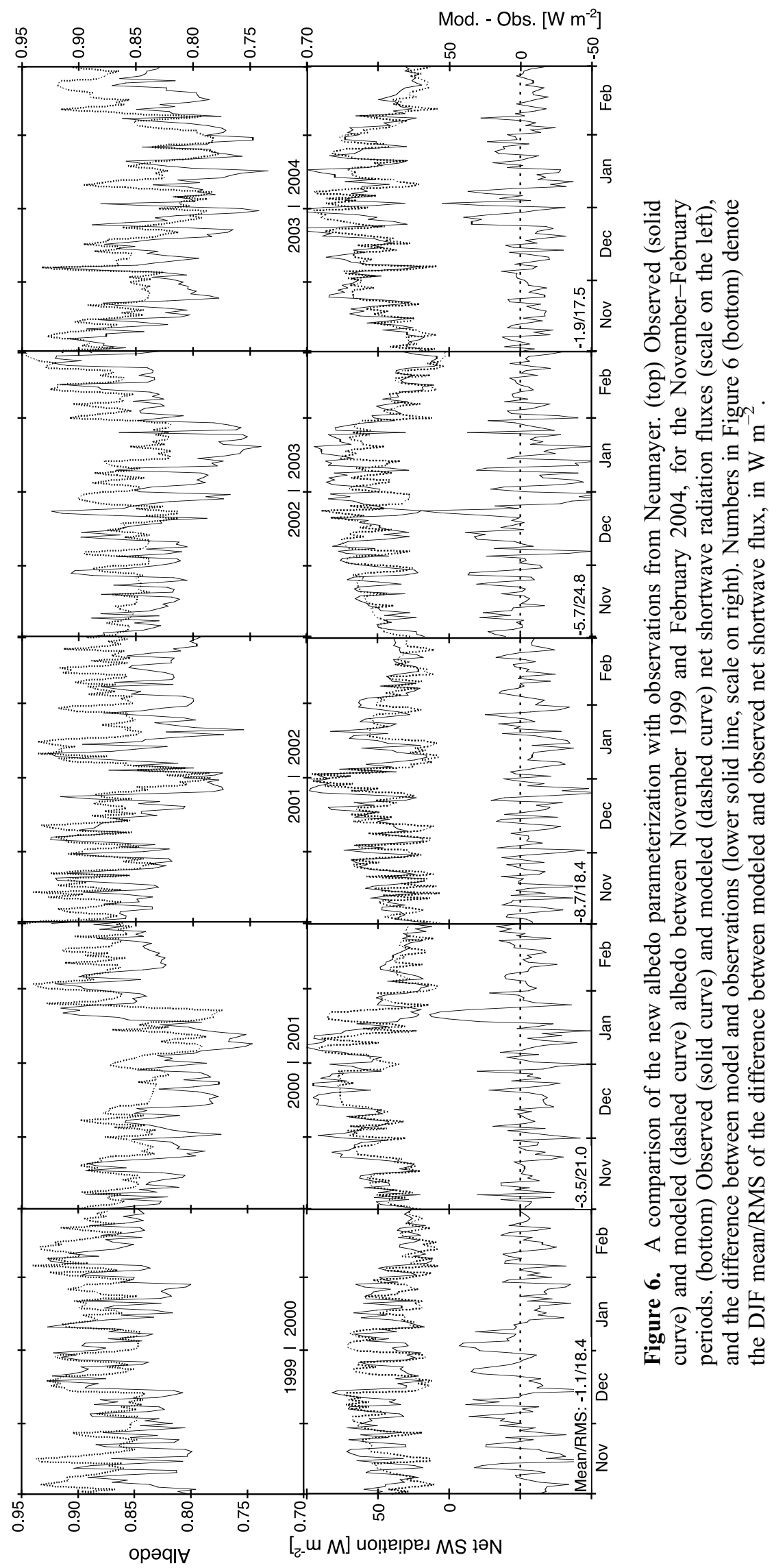




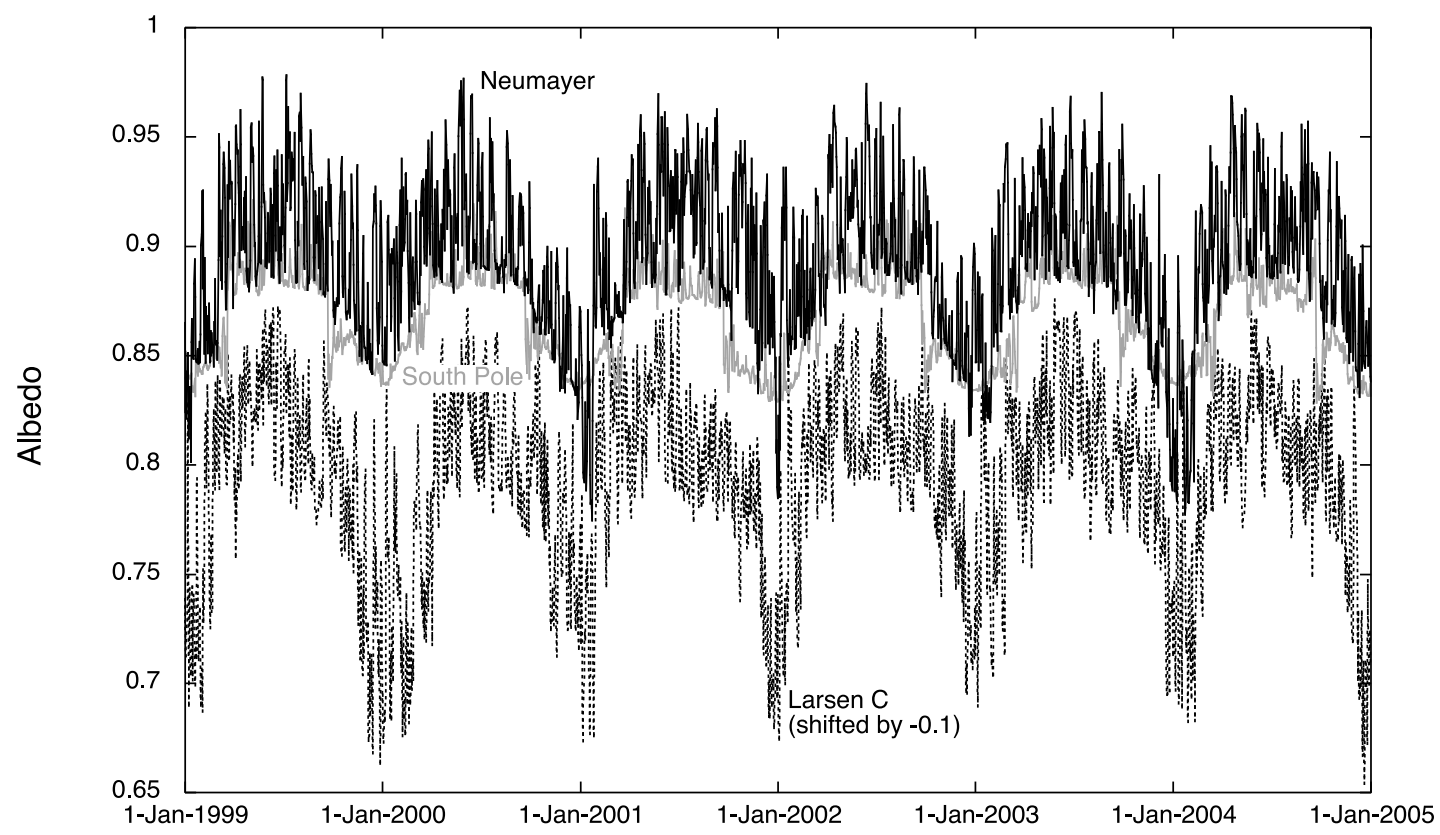

Figure 7. Results of the new albedo parameterization for three locations in Antarctica between 1 January 1999 and 1 January 2005: Neumayer (solid black curve), South Pole (solid gray curve), and Larsen C Ice Shelf (dotted black curve, shifted downward by 0.10 for clarity).

Therefore, observed large-scale albedo of ice shelves may be overestimated sometimes by RACMO2.1 in the case of strong melt events.

\section{Conclusions}

[32] A new albedo parameterization, based on snow grain size, has been implemented into the RACMO2.1 regional atmospheric climate model. To that end, snow grain size was introduced as a new prognostic variable in the snowpack. For each model layer, snow grain size evolution is computed due to dry and wet metamorphism, and due to refreezing of locally produced melt water. The albedo parameterization by Gardner and Sharp [2010] makes use of snow grain size, optical thickness of clouds, and solar zenith angle. An altitude-dependent term has been added to account for varying optical thickness of the clear-sky atmosphere.

[33] Application of the new parameterization to a 21 year run (1989-2009) over the Antarctic continent shows that the new parameterization is capable of simulating subtle variations in albedo due to small amounts of melt water and short periods of intense snow metamorphism. Moreover, the effect of cloud cover on albedo is taken care of in such a way that variability of the surface albedo is much more realistically simulated than with the old parameterization.

[34] In the application to present-day Antarctic climate, the surface is always covered with snow, and its albedo rarely drops below values for older snow of about 0.75 . For the use at locations where ice appears at the surface during the melt season, e.g., the Greenland ablation area, or typical ice caps and glaciers, the parameterization presented here needs to be extended with a part that deals with ice albedo. The expressions by Gardner and Sharp [2010] can equally be applied to ice, in which enclosed air bubbles with size $r_{e}^{\prime}$ act as scatterers in an ice medium. However, one will need either a prognostic scheme for air bubble concentration and size, or these quantities have to be prescribed. As an alternative, one could work with a fixed albedo for ice surfaces. Experiments with RACMO2.1 over the Greenland Ice Sheet addressing this issue are in progress.

[35] Now that RACMO2.1 has been fitted with a better albedo parameterization, more accurate estimates of the Antarctic mass balance and of the amount of continent-wide produced melt water are possible. For applications to the present climate, satellite observations of areal melt extent can be expanded to a melt volume. Running the model for future climate scenarios can give insights to the evolution of snow albedo and the energy budget of the snowpack in coastal regions, and of future meltwater production rates on ice shelves that may have important repercussions on the dynamic behavior of the coastal parts of the ice sheet.

[36] Acknowledgments. The authors would like to thank three anonymous reviewers for their suggestions to improve this manuscript. This research was partly funded by NWO/ALW grant 818.01.016.

\section{References}

Anderson, G. P., S. A. Clough, F. X. Kneizys, J. H. Chetwynd, and E. P. Shettle (1986), AFGL atmospheric constituent profiles $(0-120 \mathrm{~km})$, Tech. Rep. AFGL-TR-86-0110, Air Force Geophys. Lab., Hanscom, Mass.

Bougamont, M., J. L. Bamber, and W. Greuell (2005), A surface mass balance model for the Greenland Ice Sheet, J. Geophys. Res., 110, F04018, doi:10.1029/2005JF000348.

Brun, E., E. Martin, V. Simon, C. Gendre, and C. Coleou (1989), An energy and mass model of snow cover suitable for operational avalanche forecasting, J. Glaciol., 35(121), 333-342.

De Angelis, H., and P. Skvarça (2003), Glacier surge after ice shelf collapse, Science, 299, 1560-1562.

Ettema, J., M. R. van den Broeke, E. van Meijgaard, W. J. van de Berg, J. L. Bamber, J. E. Box, and R. C. Bales (2009), Higher surface mass 
balance of the Greenland ice sheet revealed by high-resolution climate modeling, Geophys. Res. Lett., 36, L12501, doi:10.1029/2009GL038110.

Fettweis, X., M. Tedesco, M. R. van den Broeke, and J. Ettema (2010), Melting trends over the Greenland ice sheet (1958-2009) from spaceborne microwave data and regional climate models, Cryosphere Discuss., 4, 2433-2473.

Flanner, M. G., and C. S. Zender (2006), Linking snowpack microphysics and albedo evolution, J. Geophys. Res., 111, D12208, doi:10.1029/ 2005JD006834.

Gardner, A. S., and M. J. Sharp (2010), A review of snow and ice albedo and the development of a new physically based broadband albedo parameterization, J. Geophys. Res., 115, F01009, doi:10.1029/2009JF001444.

Grenfell, T. C., and S. G. Warren (1999), Representation of a nonspherical ice particle by a collection of independent spheres for scattering and absorption of radiation, J. Geophys. Res., 104(D24), 31,697-31,709.

Greuell, W., and T. Konzelmann (1994), Numerical modelling of the energy balance and the englacial temperature of the Greenland Ice Sheet. Calculations for the ETH-Camp location (West Greenland, $1155 \mathrm{~m}$ a.s.1.) Global Planet. Change, 9, 91-114.

Kuipers Munneke, P., C. H. Reijmer, M. R. van den Broeke, P. Stammes, G. König-Langlo, and W. H. Knap (2008), Analysis of clear-sky Antarctic snow albedo using observations and radiative transfer modeling, J. Geophys. Res., 113, D17118, doi:10.1029/2007JD009653.

Lawrence, D. M., et al. (2011), Parameterization improvements and functional and structural advances in version 4 of the Community Land Model, J. Adv. Model. Earth Sys., in press.

Meredith, M. P., and J. C. King (2005), Rapid climate change in the ocean west of the Antarctic Peninsula during the second half of the 20th century, Geophys. Res. Lett., 32, L19604, doi:10.1029/2005GL024042.

Mitchell, D. L. (2002), Effective diameter in radiation transfer: General definition, applications, and limitations, J. Atmos. Sci., 59, 2330-2346.

Neshyba, S. P., T. C. Grenfell, and S. G. Warren (2003), Representation of a nonspherical ice particle by a collection of independent spheres for scattering and absorption of radiation: 2 . Hexagonal columns and plates, J. Geophys. Res., 108(D15), 4448, doi:10.1029/2002JD003302.

Oerlemans, J., and W. H. Knap (1998), A 1 year record of global radiation and albedo in the ablation zone of Morteratschgletscher, Switzerland, J. Glaciol., 44(147), 231-238.

Ohmura, A., et al. (1998), Baseline Surface Radiation Network (BSRN/WCRP): New precision radiometry for climate research, Bull. Am. Meteorol. Soc., 79(10), 2115-2136.

Oleson, K. W., et al. (2010), Technical description of version 4.0 of the Community Land Model (CLM), NCAR Tech. Note NCAR/TN-478+STR, Natl. Cent. for Atmos. Res., Boulder, Colo.

Reijmer, C. H., E. van Meijgaard, and M. R. van den Broeke (2005), Evaluation of temperature and wind over Antarctica in a Regional Atmospheric Climate Model using 1 year of automatic weather station data and upper air observations, J. Geophys. Res., 110, D04103, doi:10.1029/2004JD005234.

Rignot, E., G. Casassa, P. Gogineni, W. Krabill, A. Rivera, and R. Thomas (2004), Accelerated ice discharge from the Antarctic Peninsula following the collapse of Larsen B ice shelf, Geophys. Res. Lett., 31, L18401, doi:10.1029/2004GL020697.

Roeckner, E., et al. (2003), The atmospheric general circulation model ECHAM5-Model description, Tech. Rep. 349, Max-Planck-Inst. für Meteorol., Hamburg, Germany.

Scambos, T. A., C. Hulbe, M. Fahnestock, and J. Bohlander (2000), The link between climate warming and break-up of ice shelves in the Antarctic Peninsula, J. Glaciol., 46(154), 516-530.

Scambos, T. A., T. M. Haran, M. A. Fahnestock, T. H. Painter, and J. Bohlander (2007), MODIS-based Mosaic of Antarctica (MOA) data sets: Continent-wide surface morphology and snow grain size, Remote Sens. Environ., 111(2-3), 242-257.

Steig, E. J., D. P. Schneider, S. D. Rutherford, M. E. Mann, J. C. Comiso, and D. T. Shindell (2009), Warming of the Antarctic ice-sheet surface since the 1957 International Geophysical Year, Nature, 457, 459-462, doi:10.1038/nature07669.

Tedesco, M., W. Abdalati, and H. J. Zwally (2007), Persistent surface snowmelt over Antarctica (1987-2006) from 19.35 GHz brightness temperatures, Geophys. Res. Lett., 34, L18504, doi:10.1029/2007GL031199.

Undén, P., et al. (2002), The high resolution limited area model, HIRLAM-5 scientific documentation, technical report, Swed. Meteorol. and Hydrol. Inst., Norrköping, Sweden.

van den Berg, W. J., M. R. van den Broeke, C. H. Reijmer, and E. van Meijgaard (2006), Reassessment of the Antarctic surface mass balance using calibrated output of a regional atmospheric climate model, J. Geophys. Res., 111, D11104, doi:10.1029/2005JD006495.

van den Broeke, M. R. (2005), Strong surface melting preceded collapse of Antarctic Peninsula ice shelf, Geophys. Res. Lett., 32, L12815, doi:10.1029/2005GL023247.

Verseghy, D. L. (1991), CLASS-A Canadian Land Surface Scheme for GCMS. I. Soil model, Int. J. Climatol., 11, 111-133.

White, P. W. (2001), IFS documentation (CY23R4), part IV: Physical processes, technical report, ECMWF, Reading, U. K.

Wiscombe, W. J., and S. G. Warren (1980), A model for the spectral albedo of snow. I: Pure snow, J. Atmos. Sci., 37, 2712-2733.

M. G. Flanner and A. S. Gardner, Department of Atmospheric, Oceanic, and Space Sciences, University of Michigan, Ann Arbor, MI 48109, USA

P. Kuipers Munneke, J. T. M. Lenaerts, W. J. van de Berg, and M. R. van den Broeke, Institute for Marine and Atmospheric Research, Utrecht University, NL3508 TA Utrecht, Netherlands. (p.kuipersmunneke@uu.nl) 